\title{
Source and Channel Choices in Business-to-Government Service Interactions: A Vignette Study
}

\author{
Yvon Van den Boer ${ }^{1}$, Willem Pieterson ${ }^{2}$, Rex Arendsen ${ }^{3}$, and Manon De Groot ${ }^{4, *}$ \\ ${ }^{1}$ University of Twente, \\ Center for e-Government Studies, \\ Enschede, The Netherlands \\ y.vandenboer@utwente.nl \\ ${ }^{2}$ Syndio Social, Chicago, United States \\ willemesyndiosocial.com \\ ${ }^{3}$ Delft University of Technology, Delft, The Netherlands \\ rex.arendsen@gmail.com \\ ${ }^{4}$ Netherlands Tax and Customs Administration (NTCA), \\ The Research and Marketing Department \\ Utrecht, The Netherlands \\ im.de.groot@belastingdienst.nl
}

\begin{abstract}
To deal with tax matters, businesses have various potential sources (e.g., Tax Office, advisor, industry organization, friends/family) in their environment. Those sources can be coupled with an increasingly wide variety of channels (e.g., telephone, face-to-face, website, e-mail) through which information can be obtained. This has led to an increasingly complex information flow between governments and businesses. This paper provides new directions for public service delivery strategies by studying both source and channel choices of businesses using the vignette method. The findings indicate that source and channel choices are determined in different ways (i.e., positive or negative) by different factors. Furthermore, we found that source and channel choices are interrelated. It is concluded that that sources and channels fulfil different roles for information seekers. It is advisable for government to anticipate these roles in the design of their service delivery strategies.
\end{abstract}

Keywords: Source Choice, Channel Choice, Interrelation, Business-toGovernment Service Interactions, Information seeking.

\section{Introduction}

In the Netherlands, over a million small and medium-sized businesses (SMEs) regularly have to deal with various types of complex government requirements. One of the most well-known examples in this context involves managing tax problems. For several decades, governments have sought suitable service delivery strategies to

\footnotetext{
* Views and recommendations expressed in this paper are those of the individual author and do not necessarily reflect official positions or opinions of the NTCA.
} 
interact with businesses regarding these matters as efficiently and effectively as possible. For example, research on e-government and multichannel management has contributed to current strategies. The primary aim of these strategies is to guide information seekers to electronic channels, such as a website, which are assumed to be less expensive than traditional channels such as the telephone and face-to-face communication. At present, however, the use of the more costly channels remains high [e.g., 1,2]. This calls for new insights to develop revised strategies for efficient and effective service delivery.

To cope with tax matters, SMEs have various potential information sources in their environment from which to choose. The myriad sources can be coupled with an increasingly wide variety of channels through which information can be obtained. The growing number of available channels and the increasing role of other information sources have made the information flow between governments and businesses increasingly complex. As a result, it will become more difficult for governments to maintain high levels of service. This will particularly be the case if businesses do not primarily rely on the government for accurate and reliable information but instead turn to other sources because they are now easier to access than before (i.e., through the rise of new and social media) [3]. Furthermore, the increasing availability of service channels limits the efficiency with which governments can provide services to their clients (i.e., citizens and businesses). These considerations lead to the question of how governments should address the availability of numerous information sources and channels.

This situation is further complicated by a lack of theories that can help us to understand a) why businesses use certain available sources and channels and b) whether and how source and channel choices are interrelated (i.e., do businesses always use the same source-channel combination?). Although theories exist that can help us to understand a) why individuals use certain communication channels (or 'media') [e.g., 4,5] and b) the processes by which information sources are selected (e.g., Byström and Järvelin's model of information seeking [6]), there are only a few studies that clearly distinct between the source and channel and recognize their interaction, but provide no detailed explanations or determinants [e.g., 7, 8].

This paper aims to fill this gap in the current knowledge by providing insights into a) which sources and channels businesses select in business-to-government (B2G) service interactions, b) differences and similarities between source and channel choice processes by including some of the potential influencing factors for both types of choices, and c) the interrelation between source and channel choices (i.e., the channels that are used to contact various kinds of sources). With this, the paper provides new directions for public service delivery strategies as well as for future research that integrate source and channel choices.

The paper starts with a theoretical discussion about definitions of the source and channel as well as relevant theories for studying source and channel choices, followed by an elaboration of the research method. Subsequently, the results will be discussed. The paper ends with the discussion, conclusions and implications. 


\section{Theoretical Background}

This section discusses the definitions of the source and channel we use throughout this paper as well as which influencing factors for source and channel choices are recognized by theories in the media choice and information-seeking domain.

\subsection{Definitions of the Source and Channel}

For reasons of clarity, we make a clear distinction between the information source and communication channel. The source is defined as the person or organization storing the information, from whom (or which) that information can be obtained from by the seeker (adapted from Christensen \& Bailey [8]). Examples of sources are governmental agencies, advisory organizations, friends, family and colleagues. The channel refers to the means by which information is transferred between the source and seeker (adopted from [9]). Channels are viewed as equivalent to media, such as the telephone, e-mail, websites and face-to-face communication.

\subsection{Relevant Theories on Source and Channel Choices}

Theories of channel choice are primarily rooted in the media choice and use literature (e.g., Media Richness Theory [4,5], the Social Influence Model [10], and the Channel Expansion Theory [11, 12]). Theories that provide insight into source choices (and sometimes channel choices) are primarily rooted in the domain of information seeking (e.g., Byström and Järvelin's model of information seeking [6], Leckie's model of information seeking [13]). The theories in both research domains identify a wide variety of factors that have been found to be important in the selection processes of sources and channels. However, apart from the lack of definitions in many studies [e.g., 14-18], the concepts media, channels, and sources are often explained differently and seem conflated with one another [e.g., 19-21]. This hinders the determination of which exact factors influence source choices and which channel choices.

Nevertheless, the most widely recognized influencing factor, across both research areas, for source and channel choices is formed by task characteristics [e.g., 6, 9, 10, 13]. The impact of personal aspects (e.g, age, gender, education) as well as situational factors (e.g. time, distance) is recognized in several theories in both domains [e.g., 6, 9, 10, 22]. However, Baldwin and Rice [19] argue that personal aspects are only marginally of influence compared to organizational factors (e.g. organization size). Media choice theories recognize some forms of contextual influences such as social influences [10-12] and cultural norms [22]. Conversely, theories of information seeking behavior consider the context as the shaping mechanism for the entire information seeking process. Examples of contextual aspects are established interaction patterns and the information environment of organizations [7], staff and organization size, type and location of the organization and general use of sources and channels [19]. The latter seems to be equal to norms of channel use as 
proposed by the media choice theories. But also awareness of available sources in the environment of the seeker seems of importance [13]. Other influencing factors exist, but are beyond the scope of this paper since we are not able to incorporate them in the vignettes (e.g., perceived source and channel characteristics, relationship characteristics).

\section{Research Method}

Design. We used the vignette method in this study. Vignettes are short descriptions of a particular situation in which the respondents need to empathize [23]. For each vignette the respondents were asked which information source and which channel they should use in the given situation. One of the advantages of a vignette study is that it approaches reality. It is not unconceivable that the respondent is or will be confronted with such a situation and is or will be faced with such a decision [e.g., 24, 25]. A disadvantage of a vignette study is that, due to the many factors included, the amount of unique vignettes can rise quickly [26]. As a consequence we included only a few variables. Furthermore, it was chosen to confront the participants with an acceptable number of the vignettes by creating a split. This method is called the incomplete block design [26]. The unique vignettes are divided into groups and each respondent is designated to a particular group. For the current study 32 unique vignettes were formulated (five factors with each two values $\left(2^{5}\right)$ were included in each situation). Each respondent was given 4 vignettes. The manipulated variables (see table 1) were associated with characteristics of the task (i.e., complexity, importance, specificity), available time as a situational factor, and social influence (i.e., getting advice).

Table 1. Manipulated Variables in the 32 Vignettes

\begin{tabular}{|c|c|c|c|}
\hline Factor & Variables & Manipulation & As expressed in vignettes \\
\hline Task & Complexity & $\begin{array}{l}\text { 1. Simple } \\
\text { 2. Complex }\end{array}$ & $\begin{array}{l}\text {...it seems a rather simple question } \\
\text {...it seems a complex question }\end{array}$ \\
\hline Task & Specificity & $\begin{array}{l}\text { 1. General } \\
\text { 2. Specific }\end{array}$ & $\begin{array}{l}\text {.. all companies use the same } \\
\text {.. it can be quite different }\end{array}$ \\
\hline Task & Importance & $\begin{array}{l}\text { 1. Unimportant } \\
\text { 2. Important }\end{array}$ & $\begin{array}{l}\text {... the important seems not high } \\
\text {... the importance is high }\end{array}$ \\
\hline Situational & $\begin{array}{l}\text { Available } \\
\text { Time }\end{array}$ & $\begin{array}{l}\text { 1. In a hurry } \\
\text { 2. Plenty }\end{array}$ & $\begin{array}{l}\text {...there is little time } \\
\text {... no hurry, there is plenty of time }\end{array}$ \\
\hline $\begin{array}{l}\text { Social } \\
\text { Influence }\end{array}$ & Getting Advice & $\begin{array}{l}\text { Time } \\
\text { 1. None } \\
\text { 2. Getting advice }\end{array}$ & $\begin{array}{l}\text {...someone in your direct } \\
\text { environment recommends you }\end{array}$ \\
\hline
\end{tabular}

An example of a vignette is presented below. The manipulated variables are in bold, but were of course invisible to the respondents. 
Your company is doing well. Plans exist to expand the company. It could be relevant to change the legal form of your company in such a situation, however, this can be quite different from company to company. You are planning to deepen out this complex question. It is of high importance, since a change in the legal form has major consequences. Fortunately there is no hurry, because you have plenty of time to deepen out this question. Someone in your direct environment recommends you to visit an advisor to discuss the various possibilities.

Sample and Response. The study was conducted among Dutch SMEs (self-employed and businesses up to fifty employees). For an efficient and effective sampling we choose to use disproportionate stratified random sampling [27]. Underlying reason is the skewed distribution of organization size in the population. We invited $n=21000$ businesses to participate. The letters were addressed to the management of a business. They were asked to pass it on to the person in the business who is responsible for dealing with tax matters. All respondents were randomly selected from the database of the Netherlands Tax and Customs Administration (NTCA). This database was updated just before we carried out our sample survey in January 2013 and contains all registered businesses in the Netherlands. After two weeks we sent out a reminder to the businesses that had not responded yet. Finally, 6\% of all invited participants completed the survey. $68.3 \%$ of the respondents were men and $31.4 \%$ were women. $54.5 \%$ of the respondents were higher educated, $33.5 \%$ medium educated, and $12.0 \%$ low. Slightly over $80 \%$ were managing directors $(43.1 \%$ self-employed and $40.0 \%$ in a business with employees). The rest of the respondents were the specialists in the business (e.g., administrative assistant, financial employee, controller).

\section{$4 \quad$ Results}

\subsection{Selected Source-Channel Combinations}

Table 2 shows which sources are selected in throughout all vignettes. The advisor is by far the most chosen source in the given situations (62.6\%). With $20.7 \%$ the NTCA is the second most consulted source. All other potential sources are selected less often. In $5.9 \%$ of the presented vignettes the respondents did consult no source.

Table 2. Overview of chosen sources in the 32 vignettes of this study

\begin{tabular}{lrr}
\hline & \multicolumn{1}{r}{$\boldsymbol{~}$} & \multicolumn{1}{c}{$\boldsymbol{~}$} \\
\cline { 2 - 3 } NTCA & 984 & 20.7 \\
Another governmental organization than NTCA & 26 & .7 \\
Advisor/Advice organization & 2976 & 62.6 \\
A colleague within organization & 81 & 1.7 \\
An external contact who I know personal & 143 & 3.0 \\
Family or a good friend & 126 & 2.7 \\
Association (e.g., Chamber of Commerce, Industry Organization) & 127 & 2.7 \\
I consult no source & 284 & 5.9 \\
\hline Total & 4747 & 100.0 \\
\hline
\end{tabular}


Figure 1 shows which channels are used to contact various kinds of sources. The sources are shown on the horizontal axis, the channels on the vertical axis. Except for contact with family/friends and the NTCA, the telephone is the most used channel for all kinds of sources. With regard to family and friends face-to-face is the most used channel $(56.1 \%)$. Colleagues are also often consulted via face-to-face $(40.2 \%)$. In approximately a quarter of the cases, contact with the advisor $(25.4 \%)$ and association (24.9\%) occurs face-to-face. E-mail is mostly used to consult the advisor $(21.9 \%)$ and external contacts $(28.5 \%)$. The NTCA and associations are often approached via their websites (respectively, $52.7 \%$ en $18.5 \%$ ).

To study the interrelation between source and channel choice in more detail we executed a chi-square test. The results show that there is a significant association between the selected source and the chosen channel $\chi^{2}(42)=6916.12, p<.001$. The values of the standardized residuals are used to interpret the results. Agresti and Finlay [28] argue that a value greater than 3 or lower than -3 reflects a true effect. The strongest significant underrepresentations (i.e., significantly lesser selected than other combinations) were found for the combinations NTCA with face-to-face $(z=-11.3)$, advisor with the website $(z=-18.1)$, and NTCA with e-mail $(z=-8.8)$. Significant, but less strong underrepresentations exist for the combinations NTCA with the telephone $(z=-3.8)$, external contact with the website $(z=-3.9)$, and family/ friends with website $(z=-3.4)$ and with e-mail $(z=-3.6)$. The most strong overrepresented combination (i.e., significantly more often selected) is NTCA with the website $(z=36.9)$. Other strong overrepresentations concern the advisor with e-mail $(z=8.1)$, with telephone $(z=5.8)$, and with face-to-face $(z=5.4)$ as well as the combinations colleague with face-to-face $(z=6.8)$, family/friends with face-to-face $(z=9.2)$.

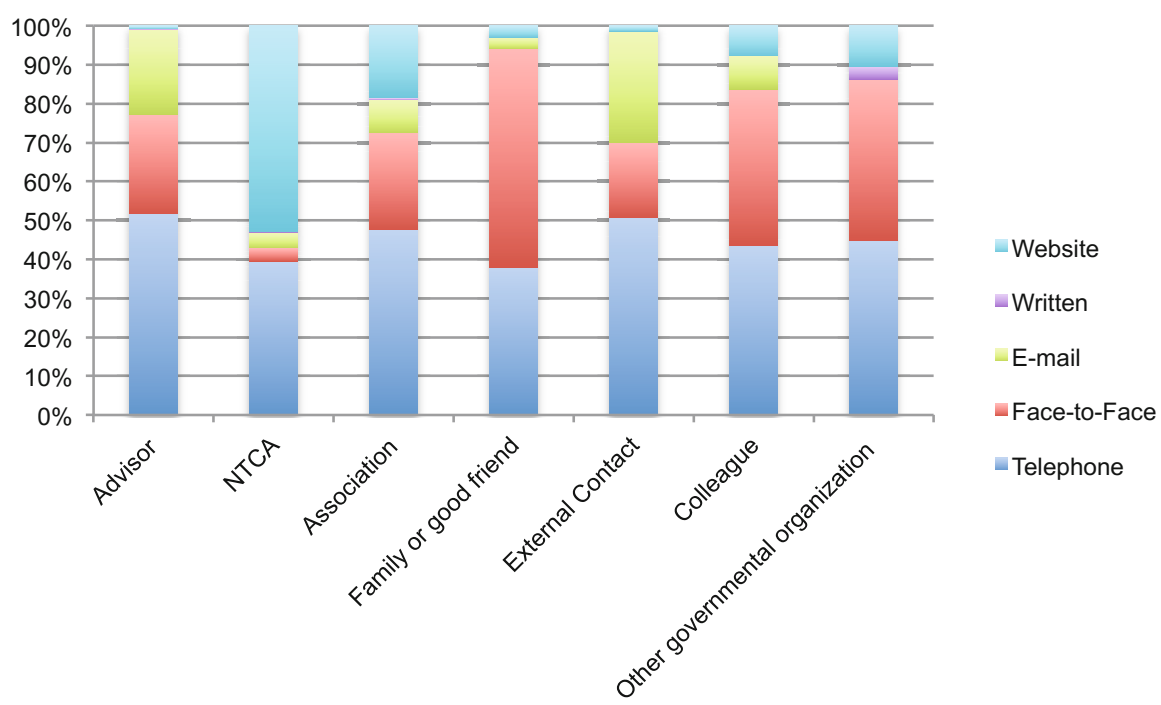

Fig. 1. An overview of the chosen source-channel combinations in the 32 vignettes 


\subsection{Influencing Factors of Source and Channel Choices}

We executed two multinomial logistic regression analyses (NOMREGs) to study the influence of the manipulated factors on source and channel choices. This section starts with the discussion of the results regarding source choices, followed by the results for channel choices.

Source Choices. The change in unexplained variance from the baseline to the final model is considered to be significant, as $\chi^{2}(63)=1467.84$ with $\mathrm{p}<.001$, which implies that the final model shows a better fit than the original model. For assessing model fit the Deviance statistic is preferred over the Pearson Statistic [29]. The Deviance statistic shows that the model fits the data well $(p=1.000)$. The pseudo R-square values of Cox and Snell and Nagelkerke show decently-sized effects with values of $R^{2}=.27$ and $R^{2}=.30$, respectively.

Figure 2 shows only the results for the two most selected sources NTCA and advisor. Table 3 in the appendix provides an overview of the results for all sources. Despite the fact that we found some similar results for both sources there are some contrasting results as well. When the task becomes more general (i.e., less specific) it is more likely that the NTCA is chosen $(b=2.51, p<.001)$, but less likely that the advisor is selected $(b=-.86, p<.05)$. Furthermore, while organization size and educational level are significant predictors for the selection of the NTCA, they do not exert significant influence on the selection of the advisor. Comparing the predictors of other sources (e.g., colleagues, associations) also brings differences to light. For instance, when as a task becomes less specific, it becomes less likely that family or friends are chosen $(b=-.90, p<.001)$, but task specificity has no influence on the selection of colleagues.
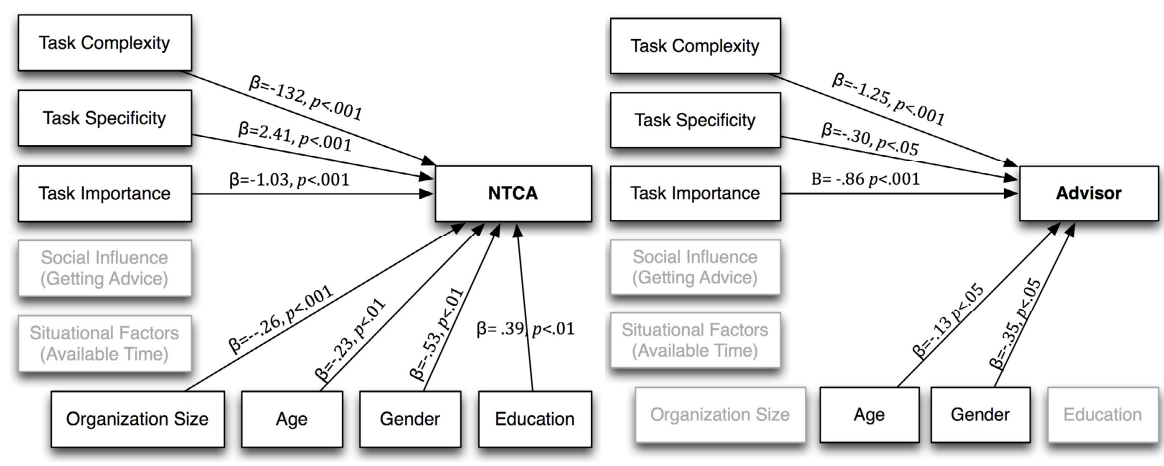

Fig. 2. An overview of the factors that influence the selection of the sources NTCA and advisor

Channel Choices. Similar to the results for source choice, the change in unexplained variance from the baseline to the final model is considered to be significant, as $\chi^{2}(54)$ $=1184.98$ with $p<.001$. The Deviance statistic shows that the model fits the data well $(p=1.000)$. The pseudo R-square values of Cox and Snell and Nagelkerke are $R^{2}=.22$ and $R^{2}=.24$, respectively. 
The website channel and the telephone channel were most selected in the vignettes. The results are presented in figure 3 . Table 4 in the appendix provides an overview of the results for all channels. When comparing the results of the website and telephone we obviously found that the selection of the website depends on more aspects than the telephone. For instance, task specificity $(b=2.17, p<.001)$ and social influence $(b=-.49, p<.01)$ are found to be significant predictors for the selection of the website, but exert no influence on the selection of the telephone. Furthermore, while gender influences both the website and telephone channel, organization size, age and education are found to be significant predictors for only the selection of the website channel and not for the telephone channel. Again, we found differences between the other channels as well. For example, When a task becomes more general (i.e., less specific) it becomes more likely that the e-mail is chosen $(b=.40, p<.05$, but less likely that face-to-face is selected $(b=-1.38, p<.001)$.
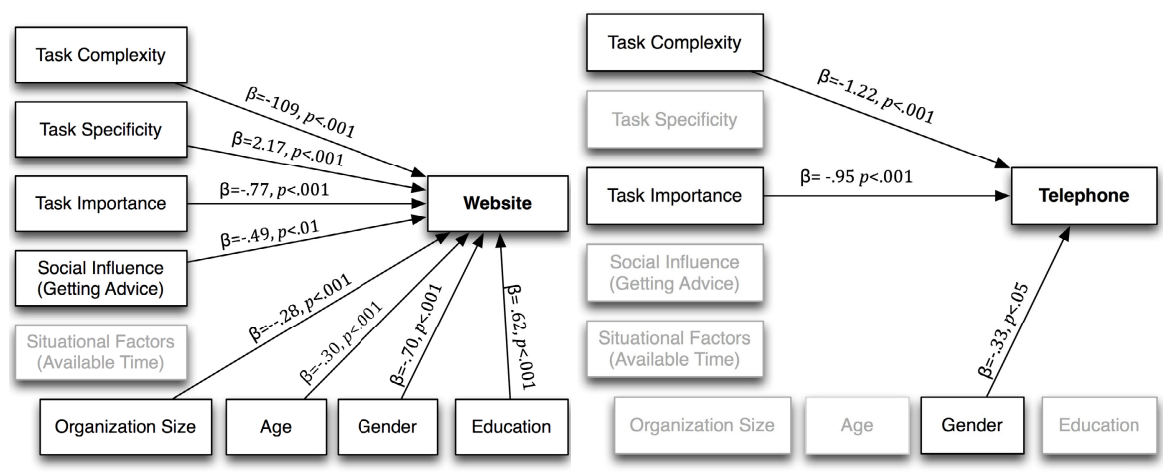

Fig. 3. An overview of the factors that influence the choice for the website and telephone

\section{$5 \quad$ Discussion and Conclusions}

The practical reason for conducting this study is the notion that despite implementing various types of strategies, the use of more costly public service channels is still high [e.g., 1,2]. Research on, for example, e-government and multichannel management, has contributed to current strategies. However, governments have failed to design effective and efficient service delivery strategies that are based on the research. We argue that a reasonable approach to tackle this issue could be to broaden the focus of current multichannel strategies by paying attention to the role of the information source related to a particular channel. Therefore, this paper examined source and channel choices in a single study, using the vignette method. This section addresses the limitations of the conducted study, followed by a discussion of findings as well as the conclusions. The paper ends with providing several implications. 
Limitations. Although the vignette method provides the opportunity to ask participants about their choices in realistic situations, a number of limitations should be noted with respect to this study. The most important limitation is that not all (potential) predictors were manipulated and incorporated in the vignettes. So, further research is needed to study the influence of other factors as well. Another issue that is not addressed is whether the participants wanted to consult a second source or channel because we only asked for their first source-channel combination. Insights into other choices throughout the information-seeking process are still needed. Further, we studied the situation in one country and in the context of B2G service interactions. This hinders the generalizability of the results to other countries and contexts.

Discussion and Conclusions. One of the more significant findings to emerge from this study is that the significance, strength and type of relationship (e.g., positive or negative) between the influencing factors and the various source and channel choices vary. This indicates that although some factors show consistent results, various aspects influence the selection of sources and channels. Furthermore, some channels were chosen relatively fewer times to consult a certain source, other source-channel combinations were significantly more chosen than others. This variety leads to the conclusion that sources and channels fulfill various roles for the information seeker.

A factor that, according to our findings, is no predictor for both source and channel choices is the situational aspect available time. This is somewhat surprisingly, since many have suggested that such aspects do play a role [e.g., 6, 7, 9, 10]. The fact that addressing tax matters is a more 'ongoing' need for businesses than it is for citizens (i.e., citizens must fill in their tax declarations only once per year) might explain the result that situational factors do not exert an influence. Because our study seems to be the first to notice this, replication and further insight is needed.

Social influences have no effect on source choices, but seem to have a marginal effect on channel choice. Although the understanding and perceptions related to the vignettes were pre-tested, the lack of influence might be due to issues in the manipulation of the social influence factor (i.e., it might be difficult for respondents to imagine themselves in such a situation). Nevertheless, our conclusion that social influences have (at least) a marginal effect on channel choice seems plausible because it is in line with the findings of many others [e.g., 10, 30- 32]. The effect of social influences on source choice seems less studied [e.g., 7], which might underline our finding that source choices are not affected by social influences.

In general, our findings indicate that task characteristics play a major role in the selection processes of source and channel choices. This result generally does not divert from other research findings [e.g., 6, 9, 10, 13, 22]. However, our contribution to the existing knowledge is the finding that the characteristic task specificity particularly determines which source and which channel will be selected, whereas the task characteristics importance and complexity are found to be action triggers (i.e., to start an information-seeking process). Furthermore, given the observed differences in the direction of the influence of task specificity, the results indicate that sources and channels fulfill various roles (i.e., some are selected for general/orientation purposes while others are selected for specific, interpretation purposes). 
The largest predictor concerning personal and organization characteristics is education, followed by organization size. Baldwin and Rice [19] argue that organizational characteristics exert more influence than personal characteristics. They even argue that individual characteristics have no influence at all. In contrast, several studies in the context of channel-choice behavior argue that these basic personal characteristics (e.g., gender, age, and education) are reliable predictors [33, 34]. Our study found that people that are higher educated are more likely to use electronic channels and consult formal sources. Larger organizations are less likely to choose the website and face-to-face. Only the advisor is independently chosen from the size of an organization, for all other sources it is observed that larger organizations are less likely to consult a source compared to no source.

Implications. The primarily starting point of current service delivery strategies is the channel of a single information source. However, our findings suggest that information seekers have many sources at their disposal to obtain information. This finding again calls for a change to incorporate the users' perspectives. Governments should realize that they act in a networked setting with various other potential sources from which businesses can obtain information. It is advisable for governments to anticipate the role of source-channel combinations. Governments can accomplish this by gaining an overview of relevant key sources in their network and determine their own role as one of those information sources in that network. The division of roles among the various sources should be considered when designing service delivery strategies. It is also important to link the role of an information source to the role of the channels that are at the disposal of that particular source. Box 1 illustrates this.

\section{Box 1-Illustration: Implications for the NTCA website}

Our findings have shown that the NTCA in combination with the website channel is primarily selected for general tasks. It would be relevant for the NTCA to consider this when developing its website. Thus, it could decide to give general information a more prominent place on the website and put more specific information in the background. Visitors are still able to obtain detailed information, but in the first instance, information overload is avoided by providing only general information. 'Decision trees' may help in structuring general and specific information. They assist visitors in selecting and finding only information that is relevant to their specific situations.

However, what if the determined roles of an information source and its channels are not the desired ones? For example, what if the findings indicate that the NTCA is often consulted to solve specific tasks, which require interpretation because the answers differ from business to business, but the NTCA primarily offers general information? In such situations, it is important to start the debate about what role the government should fulfill. What expectations should SMEs have for public service delivery? What are the responsibilities of SMEs themselves? Debating these aspects would help governments to formulate service-delivery strategies that incorporate both their own role and the advisor's role in a networked setting. Therefore, we suggest that governments should implement strategies that guide information seekers to 
desired source-channel combinations, which we call multisource and multichannel management. Cross-referrals should help guiding the seeker to another channel or other source-channel combinations. Box 2 illustrates how cross-referrals may be used in service delivery processes.

\section{Box 2-Illustration: Implementing cross-referrals}

The provided information on the website of the NTCA about how to change the legal form of a business is inadequate because there are many specific details to consider. The website can provide only general information that is applicable to every business (e.g., explanations of rules or declaration deadlines). The NTCA can add the simple sentence, 'If you want specific information whether changing the legal form would be appropriate for your business, please call or visit an advisory organization. There, they can help you with making a decision'. Also call-center employees can do this by simply telling information seekers to obtain advice from another source or via another channel.

The results of this paper indicate that sources and channels fulfil various roles for the information seekers (i.e., businesses). Despite the promising results and implications for public service delivery strategies, future research is needed to increase and refine our understanding of source and channel choices in B2G service interactions.

\section{References}

1. Pieterson, W., Ebbers, W.: The use of service channels by citizens in the Netherlands: implications for multi-channel management. International Review of Administrative Sciences 74(1), 95-110 (2008)

2. OECD: Forum on Tax Administration: Working smarter in revenue administration-Using demand management strategies to meet service delivery goals. Organization for Economic Co-operation and Development, Paris (2012)

3. Agichtein, E., Castillo, C., Donato, D., Gionis, A., Mishne, G.: Finding high-quality content in social media. In: Proceedings of the International Conference on Web Search and Data Mining, pp. 183-194 (2008)

4. Daft, R.L., Lengel, R.H.: Information richness: a new approach to managerial behavior and organizational design. In: Cummings, L.L., Staw, B.M. (eds.) Research in Organizational Behavior, vol. 6, pp. 191-233. JAI Press, Homewood (1984)

5. Daft, R.L., Lengel, R.H.: Organizational information requirements, media richness and structural design. Management Science, 554-571 (1986)

6. Byström, K., Järvelin, K.: Task complexity affects information seeking and use. Information Processing \& Management 31(2), 191-213 (1995)

7. Saunders, C., Jones, J.W.: Temporal sequences in information acquisition for decision making: A focus on source and medium. Academy of Management Review, 29-46 (1990)

8. Christensen, E.W., Bailey, J.R.: A Source Accessibility Effect on Media Selection. Management Communication Quarterly 10(3), 373-387 (1997)

9. Pieterson, W.: Channel choice: Citizens' channel behavior and public service channel strategy. Enschede, Gildeprint B.V. (2009) 
10. Fulk, J., Schmitz, J., Steinfield, C.W.: A social influence model of technology use. In: Fulk, J., Steinfield, C.W. (eds.) Organizations and Communication Technology. Sage Publications, London (1990)

11. Carlson, J.R., Zmud, R.W.: Channel Expansion Theory: A Dynamic View of Medial and Information Richness Perceptions (1), 280-284 (1994)

12. Carlson, J.R., Zmud, R.W.: Channel expansion theory and the experiential nature of media richness perceptions. Academy of Management Journal, 153-170 (1999)

13. Leckie, G.J., Pettigrew, K.E., Sylvain, C.: Modeling the information seeking of professionals: a general model derived from research on engineers, health care professionals, and lawyers. The Library Quarterly, 161-193 (1996)

14. Wilson, T.D.: On user studies and information needs. Journal of Documentation 37(1), 3$15(1981)$

15. Wilson, T.D.: Models in information behavior res. Journal of Documentation 55(3), 249270 (1999)

16. Krikelas, J.: Information-seeking behavior: patterns and concepts. Drexel Library Quarterly 19, 5-20 (1983)

17. Savolainen, R.: Everyday life information seeking: Approaching information seeking in the context of "way of life". Library \& Information Science Research 17(3), 259-294 (1995)

18. Johnson, J.D.: On contexts of information seeking. Information Processing \& Management 39(5), 735-760 (2003)

19. Baldwin, N.S., Rice, R.E.: Information-Seeking Behavior of Securities Analysts: Individual and Institutional Influences, Information Sources and Channels and Outcomes. JASIS 48(8), 674-693 (1997)

20. Boyd, A.: Multi-channel information seeking: a fuzzy conceptual model. Aslib Proceedings 56(2), 81-88 (2004)

21. Julien, H., Michels, D.: Intra-individual information behaviour in daily life. Information Processing \& Management 40(3), 547-562 (2004)

22. Sitkin, S.B., Sutcliffe, K.M., Barrios-Choplin, J.R.: A dual capacity model of communication media choice in organizations. Human Communication Research 18(4), 563-598 (1992)

23. Morrison, R.L., Stettler, K., Anderson, A.E.: Using vignettes in cognitive research on establishment surveys. Journal of Official Statistics-Stockholm- 20(2), 319-340 (2004)

24. Wason, K.D., Cox, K.C.: Scenario Utilization in Marketing Research. In: Strutton, D., Pelton, L.E., Shipp, S. (eds.) Advances in Marketing. Texas: Southw. Marketing Association, pp. 155-162 (1996)

25. Barnett, T., Bass, K., Brown, G.: Ethical ideology and ethical judgment regarding ethical issues in business. Journal of Business Ethics 13(6), 469-480 (1994)

26. Graham, M.E., Cable, D.M.: Consideration of the Incomplete Block Design for PolicyCapturing Research. Organizational Research Methods 4(1), 26-45 (2001)

27. Foreman, E.K.: Survey sampling principles. Marcel Dekker, New York (1991)

28. Agresti, A., Finlay, B.: Statistical Methods for the Social Sciences, 4th edn. Pearson Prentice Hall, New Jersey (2009)

29. Menard, S.: Applied logistic regression analysis, 2nd edn. Sage Publ., Thousand Oaks (2002)

30. Turner, J.W.: Exploring the Dominant Media: How Does Media Use Reflect Organizational Norms and Affect Performance? Journal of Business Communication 43(3), 220-250 (2006) 
31. El-Shinnawy, M., Markus, M.L.: Acceptance of communication media in organizations: richness or features? IEEE Transactions on Professional Communication 41(4), 242-253 (1998)

32. Haythornthwaite, C., Wellman, B.: Work, friendship, and media use for information exchange in a networked organization. Journal of the American Society for Information Science 49(12), 1101-1114 (1998)

33. van Deursen, A., van Dijk, J., Ebbers, W.: Why e-government usage lags behind: explaining the gap between potential and actual usage of electronic public services in the Netherlands. In: Wimmer, M.A., Scholl, H.J., Grönlund, Å., Andersen, K.V. (eds.) EGOV 2006. LNCS, vol. 4084, pp. 269-280. Springer, Heidelberg (2006)

34. van Dijk, G., Minocha, S., Laing, A.: Consumers, channels and communication: Online and offline communication in service consumption. Interacting with Computers 19(1), 7-19 (2007)

\section{Annex}

Table 3. An overview of the (in)significant influence of various factors on source choices

\begin{tabular}{|c|c|c|c|c|c|c|}
\hline Factors & NTCA & Advisor & Colleague & $\begin{array}{l}\text { External } \\
\text { Contact }\end{array}$ & $\begin{array}{l}\text { Family/ } \\
\text { Friends }\end{array}$ & Association \\
\hline Task complexity & $+/-$ & $+/-$ & $+/-$ & $+/-$ & - & $+/-$ \\
\hline Task specificity & + & $+/-$ & - & $+/-$ & $+/-$ & $+/-$ \\
\hline Task importance & $+/-$ & $+/-$ & - & $+/-$ & $+/-$ & $+/-$ \\
\hline Available time & - & - & - & - & - & - \\
\hline Social influence & - & - & - & - & - & - \\
\hline Organization size & $+/-$ & - & - & $+/-$ & $+/-$ & $+/-$ \\
\hline Age & $+/-$ & $+/-$ & $+/-$ & - & $+/-$ & - \\
\hline Education* & + & - & + & + & - & - \\
\hline Gender** & $+/-$ & $+/-$ & - & - & - & $+/-$ \\
\hline
\end{tabular}

Table 4. An overview of the (in)significant influence of various factors on channel choices

\begin{tabular}{|c|c|c|c|c|c|}
\hline Factors & Telephone & Face-to-Face & E-mail & Written & Website \\
\hline Task complexity & $+/-$ & $+/-$ & $+/-$ & $+/-$ & $+/-$ \\
\hline Task specificity & - & $+/-$ & + & - & + \\
\hline Task importance & $+/-$ & $+/-$ & $+/-$ & - & $+/-$ \\
\hline Available time & - & - & - & - & - \\
\hline Social influence & - & - & - & - & $+/-$ \\
\hline Organization size & - & $+/-$ & - & - & $+/-$ \\
\hline Age & - & - & $+/-$ & - & $+/-$ \\
\hline Education & - & - & + & - & + \\
\hline Gender & $+/-$ & - & $+/-$ & - & $+/-$ \\
\hline
\end{tabular}

Note for both tables. + significant predictor (positive effect), +/- significant predictor (negative effect),

- insignificant predictor

* reference category was "high education level", ** reference category was "women" 